\title{
Staphylococcal Food Poisoning
}

National Cancer Institute

\section{Source}

National Cancer Institute. Staphylococcal Food Poisoning. NCI Thesaurus. Code C35037.

Food poisoning that is caused by Staphylococcal infection. 